\title{
De sobremesa, novela desconocida del Modernismo*
}

$\mathrm{E}$ L descuido con que se suele encarar la contribuición del modernismo a la prosa hispánica se ha hecho tradicional. Ese lastre negativo ha impedido hasta hoy que contemos, para el estudio del modernismo en la prosa, con libros pares a los que analizan la poesía durante el mismo movimiento. No se ha publicado hasta nuestros dias una obra de conjun to sobre la novela o el cuento modernistas, o siquiera una aproximación orgánica a la suma de la prosa escrita entre r880 y r9ro bajo las direcciones del aludido ismo. Es frecuente, pues, que críticos e historia. dores pasen por alto, disminuyan o desfiguren - la cercanía con la caricatura resulta evidente- la significación que alcanzó en el mundo hispánico el cultivo de la prosa artística y la proyección de tal prosa cuando se puso al servicio del cuento y de la novela esteticistas. Las investigaciones con que contamos, algunas de $\tan$ subidas calidades como la de Amado Alonso sobre La gloria de Don Ramiro, o la de Enrique An. derson Imbert acerca de Amistad funesta, representan calas parciales y unitarias en rico conjunto que espera exploraciones más amplias y com. prensivas. 1

Repetiremos - hay que hacerlo- que la renovación modernista se ejerce, desde Hispanoamérica, primeramente en el terreno de la pro-

* Trabajo leído en la Sección Hispanoamericana, Midwest Modern Language Association, Illinois State University, reunida en Bloomington, Illinois.

1 Amado Alonso, Ensayo sobre la novela bistórica. El modernismo en "La gloria de Don Ramiro". Buenos Aires: Instituto de Filología, 1942; Enrique Anderson Imbert, "La prosa poética de José Martí. A propósito de Amistad funesté". Estudios sobre escritores de América. Buenos Aires: Editorial Raigal, 1954. pp. 125-165 Véase, asimismo, el trabajo de Alfredo A. Roggiano, "El modernismo y la novela en la América hispana". La novela iberoamericana. Memoria del quinto Congreso del Instituto Internacional de Literatura lberoamericana. Edición a cargo de Arturo Torres-Rioseco. Alburquerque The University of New Mexico Press, 1952. pp. 25-45. 
sa, y cuando nada semejante es posible señalar en la Peninsula.2 Marti y Gutiértez Nájera ${ }^{3}$ concretan con originalidad ciertas búsquedas iniciadas por autores del $\mathrm{XIX}$, en quienes era lúcida la necesidad de un cambio en el orden expresivo. La evolución fundamental se moverá entre dos polos distantes: de la ramplonería y lo in-significante, de la parálisis estética a la.écriture artiste, a la prosa de esfuerzo flaubertiano, tensa de voluntad artística e impetu original.

Desde el Romanticismo, la prosa habia empezado a valorarse de otro modo, se la despoja de toda consideración peyorativa, y la frontera artificiosa que la separa del verso desaparece para los poetas que a la vez son prosistas eximios. Escriben a la luz de una nueva verdad: la poesía puede estar en la prosa o en el verso - versos hay que de poesía tienen muy poco-, "maneras" diría Alfonso Reyes, sobre las que ella se deposita. Una modalidad antes desconocida, el poema en prosa, concreta estas nuevas posibilidades y demuestra con grado de evidencia que los poetas no dejan de serlo cuando abandonan el empleo de formas metrificadas. Notoria es la actitud orgullosa de estos escritores, los primeros en tomar conciencia firme de la aristocracia de su arte:

La llamada "literatura modernista" -escribe Anderson Imbertagrega, a los descubrimientos de la vida sentimental hechos por los románticos, la conciencia casi profesional de qué es la literatura y cuál su última moda, el sentido de las formas de más prestigio, el esfuerzo aristocrático para sobrepujarse en una alta atmósfera de cultura, la industria combinatoria de estilos diversos y la convic. ción de que eso era, en si, un arte nuevo, el orgullo de pertenecer a una generación hispanoamericana que por primera vez puede especializarse en el arte.4

Una vez que en Hispanoamérica se dieron las primeras batallas por un cambio radical en la prosa, hasta entonces mimética de adormecedores

2 Es sorprendente la afirmación de Ricardo Gullón sobre la simultaneidad del "impulso renovador" en España e Hispanoamerérica; la cronologia se encarga de desdecirla. "Y lo esencial es, a mi juicio, la simultaneidad con que el impulso renovador aparece, en Andalucía como en Chile, en Cuba como en Colombia". Direcciones del modernismo. Madrid: Editorial Gredos, 1963, p. 39.

3 Véase el reciente ensayo de Ivan A. Schulman, "José Martí y Manuel Gutiérrez Nájera: Iniciadores del Modernismo". Revista Iberoamericana, xxx (1964), núm. 57, pp. 9.50. A pesar de estas sólidas restauraciones y rectificaciones en torno a puntos fundamentales del modernismo, estudios $y$ antologías recientes conservan, tozudamente, los pareceres que imperaban hace medio siglo 7 repiten superados lugares comunes a propósito de cronología, supuestos "precursores", etc.

4 E. Anderson Imbert, estudio citado en la primera nota, p. 136. 
academizantes, pedestre, anquilosada y huérfana de conciencia artística, aparecen las obras claves de la renovación poética: el brevísimo Ismaelillo martiano (1882) y, seis años más tarde, la pequeña sección poética del primer Azul... -el de Valparaíso, Chile-, libro en que predomina lo narrativo-descriptivo, de acuerdo con la conciencia, clara en su autor por esa época, de que la prosa requería de búsquedas y experimentaciones salvadoras.

Son años de tentativas, esfuerzos, violentas negaciones - Manuel Machado habla de "la guerra literaria" en libro homónimo-, cuya característica es un marcado desvío de lo español y la voluntariosa apetencia de recoger, sobre todo del arte francés y cosmopolita, aquello que favorezca y apoye el afán de originalidad personal, al amparo paradójico del verso de Coppée que invoca Dario: "¿Qué podría yo imitar para ser original?"

Darío, en el año de Prosas profanas - año admirable del moder. nismo- al saludar la llegada de María Guerrero a Buenos Aires, explicó con precisión el porqué del desvío y el desafecto por la literatura y el pensamiento españoles de esos años:

Hemos pecado, es cierto. ¿Pero quién ha tenido la culpa sino la madre España, la cual, una vez roto el vinculo primitivo, se metió en su Escorial y olvidó cuidar la simiente moral que aqui dejaba? (...) La innegable decadencia española aumentó nuestro desvío y el verdadero o aparente aire de protección mental y de desprecio que respecto al pensamiento de América manifestaron algunos escritores peninsulares, secó en absoluto nuestras simpatías. y nos alejó tanto de la antigua madre patria, que la actual generación intelectual, los pensadores y artistas que hoy representan el alma americana, tienen más relación con cualquiera de las naciones de Europa que con España. Hijos malos, llegamos a afrentarnos de nuestra madre empobrecida. Al mismo tiempo en el Río de la Plata se realizaba el fenómeno sociológico del nacimiento de ciudades únicas, cosmopolitas y poliglotas, como este gran Buenos Aires; flor enorme de una raza futura. $Y$ tuvimos que ser entonces poliglotas y cosmopolitas y nos comenzó a venir un rayo de luz de todos los pueblos del mundo...

En medio de ese aire nuevo, aire tenso de negaciones y renovaciones; nace y se desarrolla la novela modernista, enlazada a dos propósitos

5 Rubén Dario, "Maria Guerrero". Rubén Dario. Escritos inéditos, Enwin K. Mapes, editor. New York: Instituto de las Españas, 1938. p. 125. 
fundamentales del arte nuevo: crear una prosa original y sabia e incorporar a la literatura narrativa, en atmósfera intelectual propicia, a un nuevo héroe, heredado del romanticismo con ropaje de pequeño dios: el artista. ${ }^{5 a}$ Como Vigny, adoran ellos a una divinidad recién llegada: la aristocracia de la inteligencia.

La literatura de ficción escrita bajo el signo modernista aporta a la categoría del personaje, con intensidad antes no conocida, poetas, músicos, pintores, estetas, escultores, pensadores en función protagónica y como revelación o apertura hacia un mundo al que no todos los profanos tienen acceso. También en este sentido la ficciớn modernista siguió un aspecto que puede establecerse como constante de la novela francesa. ${ }^{6}$ A la vez, la novela del modernismo se solaza en la pintura de los rebeldes hijos de la insatisfacción, las víctimas del spleen, los neurópatas, los seres de refinamiento enfermizo y sensibilidad hiperestésica - palabra dilecta de esos años - que hizo correr por el mundo literario el encendido culto de Joris $\mathrm{K}$. Huysmans y su más célebre personaje, Des Esseintes. ${ }^{7}$

La narración del modernismo - cuando no elige el camino de la evasión temporal y geográfica- entroniza a los raros, en medio de una atmósfera intelectualizada y obsedida por el "delirio de arte". Herederos en mucho de la tradición romántica, estos escritores entréganse al culto sagrado del artista y a la protesta por la incomprensión de éste en una sociedad practicista y vulgar, que da por tierra con todo sueño y ambición de espíritu, mientras practica los mentidos mecenazgos que denuncia El rey burgués dariano. ${ }^{8}$

5t En un estudio que se escribiese sobre la presencia del artista y del intelectual como héroe en la narrativa hispanoamericana, un capitulo importante tendría que destinarse a tal presencia en la literatura del modernismo Para ese tema, desde Goethe a Joyce, y con especial referencia a la novcla en lengua inglesa, puede verse el libro de Maurice Beebe, Ivory Towers and Sacred Fottnts. The Artist as Hero in Fiction from Goethe to Joyce. New York: New York University Press, 1964.

6 Véase sobre este punto el libro de Victor Bromberg, The Intellectual Hero. Studies in the French Novel. 1880-1955. Chicago: The University of Chicago Press [Phoenix Books], 1964. Cp. especialmente pp. 11-40.

7 No queda duda de que uno de los libros que más tiene en cuenta Silva al escribir $D e$ sobremesa es $A$ Rebours de J. K. Huysmans. Hace años fue señalado por J. M. Monner Sans el hecho de que "La novela de Huysmans interesó mucho a los modernistas americanos. Algunos la tuvieron como manual del perfecto decadente y quizá creyeron que apropiarse o parafrasear los juicios estéticos de Des Esseintes era inequívoca muestra de distinción intelectual..." Juliän del Casal y el modernismo bispanoamericano. México: El Colegio de México, 1952. p. 98. Cp. Ia nota de Elaine D'Entremont, "The Influence of Joris Karl Huysmans' $A$ Rebours on Rubén Dario". Romance Notes, V (1963), pp. 37-39.

8 Véase el estudio de Edmundo García-Gitón, "Fl modernismo como evasión cultural". La cultura y la literaturat iberoamericanas. Memoria del Séptimo Congreso del Instituto Internacional de Literatura Iberoamericana. 1957. pp. 131.138. 


\section{Ambito intelectual de SILVA}

AI héroe que alzan las crecientes sociedades nuevas, el hombre práctico y positivo, el banquero, el político falaz y entiquecido con la inversión generosa de sus promesas, al triunfador de la hazaña bursátil y financiera, oponen los nuevos escritores, con indisimulado orgullo de clase espiritual, al inconformista y al desadaptado. En algunas de las creaciones principales del modernismo en la literatura narrativa llegamos a conocer la fórmula de pacto o de lucha de tales escritores con la sociedad de sus días, a través de tópicos esenciales: huída o evasión, anatema, sátira a la mediocridad triunfante, burla del falso mecenazgo. ¿Cómo no recordar ciertas figuras que son clave de este asunto, como el poeta de " El rey burgués", enfriándose bajo la ventisca, asido a su manivela, mientras en palacio beben y comen hasta hartarse el profesor de farmacia, el "fazedor" de ditirambos y el seudo artista que por poco se alquila? ¿O el desolado adiós a la patria del personaje de Idolos rotos, al ver pisoteados su arte y su ideal por los mílites de turno, en una demasiado eterna "hora de la espada"?

En esta guetra finisecular se combate en reciprocidad: al manotazo despectivo de una sociedad hostil, incomprensiva y empedernida en la poca luz de su angosto horizonte - el triunfo práctico-, bien pueden los escritores oponer su exaltado culto del arte como verdad y. religión sumas o quejarse, como lo hacía Darío, del tiempo en que les tocó nacer.

En una de sus prosas, "Carta abierta", epistola literaria en que sopla algún airecillo becqueriano, dirá José Asunción Silva a su destinataria, una artista:

...usted y yo, más felices que los otros que pusieron sus esperanzas en el ferrocarril inconcluso, en el ministro incapaz, en la sementera malograda o en el papel moneda que pierde su valor, en todo eso que interesa a los espíritus prácticos, tenemos la llave de oro con que se abre la puerta de un mundo que muchos no sospechan y que desprecian otros; de un mundo donde no hay desilusiones ni existe el tiempo; es que usted y yo preferimos al atravesar el desierto, los mirajes del cielo a las movedizas arenas, donde no se puede construir nada perdurable; en una palabra, es que usted y yo tenemos la chifladura del arte, como dicen los profanos, $y$ con esa chifladura moriremos. Señora, déjelos usted que nos llamen chiflados, que se burlen de nuestra inocente manía. 
Ya ve usted cómo al cabo de dos años nosotros adoramos con más fervor lo que queriamos entonces, $y$ ellos han perdido sus ilusio. nes...9

\section{"LO MEJOR DE MI OBRA..."}

Conocemos hoy de modo incompleto a Silva, el poeta y el prosista, puesto que nos falta gran parte de la obra que produjo. Y lo que es peor, nos falta de esa obra la que corresponde a los últimos años de su existencia torturada, cuando le escribia a su confidente Baldomero Sanín Cano que necesitaba como nunca cuidar su "jardín interior para no sentir tan intensamente el vacio de esta vida". 10 "Sombras semejantes cubren buena parte de la vida de Silva, a la que muchos seudo biógrafos han colaborado con episodios grotescos cuando no malignos. Parece haber recaído sobre el desventurado Silva el vaticinio oscuro del personaje de De sobremesa: "sobre mi cadáver todavía tibio, comenzará a formarse la leyenda que me haga aparecer como un monstruoso problema de psicológica compli. cación ante las genetaciones del futuro"."11

Entre las varias fatalidades que contribuyeron al final derrumba. miento de J. A. Silva, una hay que repercute en su desconocimiento actual como prosista y narrador del modernismo: el naufragio del Amérique, en el que regresaba Silva desde La Guayra a su país. A principios de 1895 - dieciséis meses antes de su suicidio- pierde el escritor, como él mismo anotó, "lo mejor de mi obra". En esa desgraciada circunstancia - de la que fue testigo un poco lejano Enrique Gómez Carrillo- Silva perdió la primera redacción de De sabremesa, la colección Los cuentos negros y una parte considerable de su obra poética: Los Poemas de la Carne y la serie de sonetos cuyo título habría sido, de llegar a publicarse, Las almas muertas. Se conocen sólo por su nombre otras dos novelas - acaso simples nouvelles- del autor: Ensayo de perfumería y Del agua mansa.12 Alberto Miramón habla de "seis novelas" escritas por el poeta colombiano. ${ }^{13}$ Habría

- J A. Silva, "Carta abierta". Obra completa (Prosa y verso). Bogotá: Litografía Villegas [Biblioteca de Autores Colombianos, 99]. p. 44. Las citas de De Sobremesa se harán por esta edición, a pesar de que su descuido tipográfico la bace digna de desconfianza.

10 Obra completa, p. 434.

11 Obra completa, p. 254.

12 Cp. Antonio Curcio Altamar, Evolucion de la novela en Colombia. Bogotá: Publicaciones del Instituto Caro y Cuervo, XI, 1957. p. 176.

13 Alberto Miramón, José Asunción Silva. Bogotá: Litografía Villegas [Biblioteca de Autores Colombianos, 110], segunda edición, 1957. p. 256. 
que entender que no todas ellas alcanzaban la extensión de De Sobremesa y que en tal suma se contarian cuentos y novelas.

Perdida su obra frente a las costas de Colombia, Silva reconstruyó úni. camente De sobremesa, a petición de un amigo. Después del suicidio del autor, su diario novelado tardó casi treinta años en ser editado completo; ${ }^{14}$ de haberlo publicado en vida, el mismo ambiente que lo ignoró con insolencia, difícilmente hubiérale perdonado un libro audaz, uno de los mejores itinerarios para recorrer su pensamiento torturado.

\section{Aproximación a la NOVEla}

Acaso ninguna otra novela escrita en el modernismo nos trasmite tan fielmente como De Sobremesa el enrarecido intelectualismo imperante en el fin de siglo exquisito y problemático. Ninguna como la obra de Silva da una muestra tan cabal de lo que era esa incesante "plática de arte" y el carácter libresco del mundo en que se desplazaban los primeros modernistas. Razón ha tenido Bernardo Gicovate al estudiar De sobre. mesa como vivo testimonio o eco americano de la decadencia europea. ${ }^{15}$ Pero nada encontraremos en la novela de imitaciones rubendariacas, término que el colombiano acuñó para designar a los imitadores anémicos de Darío, aquellos de los que éste decía no tener la culpa, puesto que fue claro al postular el acratismo básico del movimiento. De sobremesa no ilustra tanto la estilistica del modernismo (como Amistad funesta o La gloria de don Ramiro) cuanto sus modalidades interiores, al amparo de lo que Silva entendía como el arte nuevo de la novela:

En manos de los maestros la novela y la crítica son medios de presentar al público los aterradores problemas de la responsabilidad humana y de discriminar psicológicas complicaciones; ya el lector no pide al libro que lo divierta sino que lo haga pensar y ver el misterio oculto en cada partícula del Gran Todo. ${ }^{16}$

14 Sólo apareció en 1928.

15 Bernardo Gicovate, Conceptos fundamentales de literatura comparada. Iniciación de la Poesia Modernista. San Juan de Puerto Rico: Ediciones Asomante, 1962. Véase el capitulo V: "José Asunción Silva y la decadencia europea", donde se encuentran observaciones muy importantes en torno a De sobremesa y el culto de Silva por los prerrafaelitas.

$16 \mathrm{Cp}$. Brombert, The Intellectual Hero, ob. cit. en la nota 6 , quien afirma en la p. 16, recordando el vaticinio de los Goncourt: "the brothers Goncourt, whose nervous antennae made them perceptive of all new trends, prophesied that the novel of the future was bound to concern itself more with "what happens in the brain of humanity" than in the heart [Joumal, July 16, 1856]". Silva dijo cosas muy parecidas sobre el porvenir de la novela, 
La lectura de De sobremesa muestra que Silva, sin estar premunido de una técnica narrativa hábil - buen prosista, pero novelista inexpertoquiso hacer una novela psicológica - no en vano su admiración por Bourget y por J. K. Huysmans-, reveladora de las complicaciones del alma de un artista que vaga entre místicos deliquios e himnos a la carne y.la desnudez sensual. De sobremesa, como libro de muy valiosas revelaciones epocales - iunque sobrepasa los reducidos límites y bogotanos-, recoge los intereses por la psicologia, la psicopatología y la parapsicología, más las exploraciones mentales de los años que el autor conoció directamente, cuando París se deslumbraba con Charcot y otros estudiosos prefreudianos.

Por ser la suya una novela de audaz exploración en la psicología de un artista, Silva elige una modalidad narrativa, el "diario" -que nos es revelado en una larga lectura "de sobremesa"-, generosamente expresivo de la intimidad de un carácter. En De sobremesa el novelista nos lleva en peregrinación europea con José Fernández, rico poeta colombiano, neurópata que persigue a una misteriosa Helena, evasiva figura vista más en los cuadros que en la realidad, y que encarna lo imposible, la aspiración a "lo azul", el arte, cuyos dominios no se entregan, aunque se persiga la forma perfecta. "En estos últimos días del año sueño siempre en es. cribir un poema, pero no encuentro la forma...", escribe Fernández, revelando a su creador, en un fragmento que nos hace recordar el último poema de Prosas profanas, ese que abre las futuras grandes interroga. ciones de la poesía dariana.

El diatio-novela de Silva, mirado bajo esta luz, conviértese en clave de acercamiento a una psicologia muy representativa de fin de siglo y del registro de inquietudes del propio autor - lo que no quiere decir que invitemos a la confusión entre la figura creada por el escritor y su persona histórica-; le interesó a Silva en su novela, más que disponer una sutil mecánica narrativa, exhibir sin ambages la tortura interior, el drama, el vacío, la soledad de un "raro" en medio de una sociedad pacata y atrasada, los ascensos y caídas de un hombre que, en muchas páginas, se acerca a la identificación con sus propios sueños y frustradas ambiciones. No olvidemos, por otra parte, que esas páginas se escriben, primero, y se reconstruyen, después en los días más torturados del poeta, "pues por ese tiempo comenzaban las amenazas judiciales, la escasez de dinero, la búsqueda de empleo y otras circunstancias adversas que amargaron la vida 
de este Alcibiades santafereño, dotado de una tremenda capacidad para el delirio imaginativo", escribe Rafael Maya. ${ }^{17}$

En su mayor parte esta novela-ensayo presenta una asistemática teoría del hombre finisecular y de sus conflictos básicos. La constante interpre. netración genérica (la invasión de lo ensayistico y meditativo en el campo propio de la ficción) confiere al libro una estructura a veces caótica, vaticinio de La vorágine, cuyo exaltado protagonista es, como José Fernández, poeta y espejo del autor. En este desorden narrativo, al que con. tribuye la disposición de la novela "itinerante", el hilo regente o estruc. turante es la persona de Fernández, minuciosamente estudiado en sus búsquedas $e$ insatisfacciones.

\section{Esteticismo. "Cuadros" e "interiores"}

El narrador del modernismo no pierde oportunidad de embellecer y de encarecer la proyección estética de objetos y situaciones. Un recurso frecuente es el logro de una nueva forma de naturaleza, ya capturada en la obra de otros artistas, especialmente en la de los pintores. Como los modernistas se desplazan en una atmósfera bastante cargada de "experiencias de cultura", no es raro que su prosa sea museica y neobarroca -lo fundamental de este neobarroquismo se da en el orden de estrechar, como en el siglo diecisiete, las relaciones entre la pintura y la poesía, en cabal fusionismo. El aǵán pictórico de la literatura de Silva queda muy claro si recordamos una apetencia suya anotada en el texto que lleva por título "Carta abierta": "lograr que las palabras digan ciertas impresiones visuales".18 Por lo mismo no sólo encontramos "arte dentro del arte" - la pintura incorporada de varios modos a la literatura, entre ellos las "transposiciones" - sino una ostensible tendencia, manifiesta en De sobremesa, a detener el avance de la obra en "cuadros" y "escenas" pictóricos y plásticos, llenos de refinamiento cromático.

Véase el comienzo "pictórico" de la novela: un cuadro de interiores exquisitos, el perfecto salón del modernismo:

Recogida por la pantalla de gasa y encajes, la claridad tibia de la lámpara caía en círculo sobre el terciopelo carmesí de la carpeta, y al iluminar de lleno tres tazas de China, doradas en el fondo

17 Cp. Rafael Maya, Los origenes del modernismo en Colombia. Bogotá: Biblioteca de Autores Colombianos, 1961. p. 66.

18 Obra completa, p. 445. 
por un resto de café espeso y un frasco de cristal tallado, lleno de licor transparente entre el cual brillaban particulas de oro, dejaba ahogado en una penumbra de sombría púrpura, producida por el tono de la alfombra, los tapices y las colgaduras, el resto de la estancia silenciosa.

En el fondo de ella, atenuada por diminutas pantallas de rojiza gasa, luchaba con la semioscuridad circunvecina, la luz de las bujias del piano, en cuyo teclado abierto oponia su blancura brillante el marfil al negro mate del ébano.

Sobre lo rojo de la pared, cubierta con opaco tapiz de lana, brillaban las cinceladuras de los puños y el acero terso de las hojas de dos espadas cruzadas en panoplia sobre una rodela, y destacándose del fondo oscuro del lienzo, limitado por el oro de un marco florentino, sonreía con expresión bonachona la cabeza de un burgomaestre flamenco, copiada de Rembrandt... ${ }^{19}$

Desde el comienzo del libro nos enfrentamos con una técnica que será frecuente en los capítulos de De sobremesa: la pintura (Rembrandt Rubens, Redon; los prerrafaelitas, el Españoleto y tantos otros) como elemento que prestigia y ennoblece, como sabia nota de museo. Por esta misma via, se hará frecuente la presentación de personajes apoyada por la mención de parecidos y similitudes pictóricos, lo que crea un halo aristocrático y precioso. En su visión de Helena, el novelista dispone un cuadro de movimientos rituales y misteriosos;

[las cortinas] se levantaron un momento después y me dejaron ver en el fondo oscuro del aposento la luz de la lámpara que ardía cobijada por amplia pantalla de gasa. Volviéndole las espal. das, caminó de frente la silueta negra y larga, como la de una virgen de Fray Angélico...20

El arte -recuérdese el estudio de este subtema de la poesía dariana por Pedro Salinas-y la pintura serán, asimismo, refugio y remedio

19 Obra completa, p. 191. Cp. el "interior" del departamento de María Legendre "La salita con las paredes tendidas de una sedería japonesa, amarilla como una natanja madura, y con bordados de oro y de plata hechos a mano, amueblada soberbiamente con muebles que habrían satisfecho las exquisiteces del esteta más exigente; la alcoba tapizada de antiguos brocateles de iglesia, desteñidos por el tiempo, con su mobiliario auténtico del siglo xvı y el cuarto de baño, donde lucia una tioa de cristal opalescente como los vidrios de Venecia, junto a las mesas de tocador, todas de cristal y nikel, sobre la decoración pompeyana de las paredes $y$ del piso...", p. 235.

20 Obra completa, pp. 272-273. 
ante el "tnal de vivir". Huyendo del mundo agresivo y torpe ( $\iota^{\text {"Tú }}$ crees que yo me acostumbro a vivir?", pregunta nuestro héroe a menu. do) el protagonista logra el olvido, la paz, y permanece "encerrado en iglesias o museos o soñando por horas enteras en amorosa contempla. ción ante las obras de [sus] artistas predilectos, como el Sodoma y el Vinci..."21

La pintura crea en el personaje de De sobremesa imaginaciones y ver. daderas galerías de sueños. La inasible Helena, de la que se dice pertenece a la familia de la mujer de Rossetti, esa sombra que José Fernández nunca alcanzará, ha nacido primero en su mente cuando contempló, niño, ciertos cuadros en Londres. Más tarde, esta fijación infantil se deposita en la hija del conde Roberto de Scilly, a la que el protagonista seguirá por toda Europa. Sabrá de ella, más tarde, pero ése será un momento de poética e irrestañable melancolía, iluminado por el recuerdo de Poe, que tanto leyó Silva: la muerte de una mujer joven, hermosa y admirada, ante cuya tumba no cabe sino la meditación elegiaca

Las alucinaciones pictóricas que pueblan la mente dislocada de Fernández se presenta a menudo:

Ante mi imaginación sobreexcitada y que había perdido la noción de la realidad, el oro de los cabellos sueltos, heridos por la luz de las bujias, revistió el brillo de una aureola que irradiaba sobre el fondo oscuro del comedor...22

Las evocaciones de museo despertadas por la hermosura de Helena son precisas. En el primer encuentro con ella aparece claro el afán de trasposición o de fusión de artes, que nos lleva a pensar en el barroco. La primera mirada del personaje encuentra en ella "cierto parecido, por su forma extraña, con el retrato de una princesita hecho por Van Dyck, que está en el museo de La Haya". ${ }^{23}$ Líneas después, se quita ella los guantes y él descubre, con ojos de pintor, dos manos.

largas y pálidas, de dedos afilados como los de Ana de Austria en el retrato de Rubens. ${ }^{24}$

$Y$ en el mismo fragmento, finalmente, observa el perfil de Helena,

21 Obra completa, p. 200.

22 Obra completa, p. 269.

23 Obre completa, p. 264.

24 Obra completa, p. 265. 
y lo enmarca rigurosamente para la contemplación "pictótica", de perfecta efigie:

El otro perfil, el de ella, ingenuo y puro como el de una virgen de Fra Angélico, de una insuperable gracia de líneas y de expresión, se destacaba sobre el fondo sombrío del papel del comedor, iluminado de lleno por la luz del candelero. Completaban su belleza los cabellos, que se le venían y le caían sobre la frente estrecha en abundosos rizos, con el busto largo y esbelto, vestido de seda roja, las manos blanquísimas y finas... ${ }^{25}$

No en vano había estudiado Silva en los museos de Europa y pintado antes de sus veinte años. Esta última habilidad suya, poco conocida, no sólo nos explica la sensibilidad pictórica que muestra su novela, sino su aguda vigilancia cromática, manifiesta en prosa y poesía.

\section{"ESTE FIN DE SIGLO ANGUSTIOSO"}

De sobremesa, la novela exaltadamente cosmopolita y universalista, minuciosa para referimos el tormento y la exquisitez psicológicos del "caso" José Fernández, resulta paradoja si la referimos a la Bogotá de fin de siglo, impermeable a muchos cultos foráneos - como el naturalismo, seguramente condenado por herético. En verdad, pocos libros escritos en el último decenio del siglo diecinueve registran mejor la angustiosa conciencia del hombre finisecular $y$ la seguridad que éste tiene de vivir en una "época mediocre y ruin", ${ }^{26}$ que exacerba el mal de vivir y el "asco de la vida". 27

La conciencia de vaciedad, de tedio, el sentimiento de incomunicación y ajenidad, llevan al protagonista a perseguir, a todo precio, las emociones nuevas $y$ estremecedotas, a tentar toda suerte de embriagueces anestesiantes. Lo que hace Fernández es buscar un adormecedor espiritual que le permita atravesar indemne por un interminable panorama de mediocridades. En sus labios se hará constante, en múltiples variedades, esta inquisición: "¿qué es la vida real, dime, la vida burguesa, sin emociones y sin curiosidades?".28 Pregunta a la que rodea una constelación

25 Obra completa, p. 266.

Obra completa, p. 384 .

Obra completa, p. 401.

Obra completa, p. 199. 
conveniente de asedios sensuales cada vez más complicados e inútiles para el buscador de novedades intensas:

"he abandonado ... Ios planes de mis poemas, y los negocios, para vivir preocupado sólo de placeres, de sport, de fiestas, de esgrima, en una incesante caceria de setisacione's...";

"lo anormal me fascina como una prueba de rebeldía del hombre contra el instinto...";

"Pasé ... la noche aquí viendo una serie de aguafuertes y de acuarelas que me ofrecen en venta; total: ninguna emación fuerte. . ."2s

De todas sus búsquedas, regresará José Fernández con las manos vacias. A propósito de esta situación interior torturada de su personaje, Silva intentará una de las primeras indagaciones que conoce la novela hispanoamericana en las honduras y complicaciones animicas de un personaje anormal, sombrio $y$ nihilista. Funda a la vez la alta novela, la novela del arte, lleva a su máxima tensión la literatura dentro de la literatura, por los mismos derroteros que su maestro Huysmans, cuyo $A$ Rebours está siempre presente en estas páginas. ${ }^{30}$

Para el dramático inquirir del protagonista,

"¿y qué me importan esas ideas sobre el amor, ni qué me importa nada, si lo que siento dentro de mi es el cansancio y el desprecio

29 Obra completa, pp. 237, 239, 281.

30 Cp. innumerables fragmentos de De sobremesa que hacen a Fernández pariente muy cercano de Des Esseintes, hasta en el gusto por las flores inimaginables, producto de asombrosos cruces vegetales (las "orquídeas monstruosas", $p$. 195 de Obra completa). Un amigo le dice a Ferníndez su admiración por el ambiente que éste crea a su alrededor: "El lujo enervante, el confort refinado de esta casa con sus enormes jardines llenos de flores y poblados de estatuas, su parque centenario, su invernáculo donde crecen, como en la atmósfera envenenada de los bosques nativos, las más singulares especies de la flora tropical...", p. 203, donde se habla extensamente del agotamiento sensual a que corre Fernández. Por otra parte, el hablar constantemente de arte y de literatura es rasgo exacerbado por Huysmans. Fernández confiesa, p. 311, "todo se complica dentro de mi, y toma visos literatios, una curiosidad se agrega a otra, los atractivos de la obra de arte me hacen olvidar los más graves intereses de la vida...", y poco más adelante, p. 323, se refiere a su "eterna manía de convertir (sus) impresiones en obra literaria".

El iuicio de Baudelaire ("el más grande para los verdaderos letrados, de los poetas de los últimos cincuenta años", p. 308) traduce, por cierto, la admiración del propio Silva, pero no habria olvidado el elogio del autor de las Flores del mal que aparece en el cap. XII de $A$ Rebours: "Baudelaire était allé plus loin: il était descendu jusqu'au fond de l'inépuisable mine, s'était engagé à travers des galeries abandonnées ou inconues, avait abouti à ces districts de l'âme où se ramifient les végétations monstrueuses de la pensée". I. K. Huysmans, $A$ Rebours, Paris: Bibliothèque-Charpentier, s.f., p. 189. 
por todo, el mortal dejo, el spleen horrible, el tedium vitae que, como un monstruo interior cuya hambre no alcanza a saciarse con el universo, comienza a devorarme el alma ... ?' 31

queda un refugio posible: el arte, guia y luz en el caos y la ceguera espiritual. El arte que exige culto religioso y diario, único oxígeno respirable para esta categoria de desencantados. No hablar de arte, no atizar ese fuego sublime aparece ante el protagonista como la condenación más severa, $;$ alguna vez, para traducir la opacidad de alma de un pariente oscuro, lo clava en la pared con esta etiqueta de decepción: "no hablamos nunca de arte". 32

Es que el subido clima intelectual puesto en circulación por el modernismo - mostrando claramente en esta imperfecta novela reveladorase ampara en un delirante, incansable "vivir de poesía". Asi entendemos mejor el por qué de la intensidad, en De sobremesa, de la plática y la me. ditación artísticas.

\section{Aristocracia Mental y Mediocridad}

Cuando la masa ignora el canto, es lícito verterlo sólo hacia el reino interior, postuló Darío. El después, afortunadamente, abjuró de esta posición exclusivista e hizo poesía sermonaria, de alerta continental, y llegó a preocuparse de esos presidentes de república que prometiera no cantar, pues la política, dijo al frente de Prosas profanas, pudiera enturbiarle la ensoñación dirigida a la corte de Halagabal. Cuando se recuerda estas notas del modernismo es justo entenderlas como respuesta del artista a la chatura circundante, al desprecio por el arte manifiesto en las ideolo. gías de los hombres prácticos, y contra la crítica ejercida por paralíticos intelectuales, mezquinos "amantes de la lija y la ortografía", como dijo Darío, al que pertenece la orgullosa advertencia de que "el arte no pone los puntos sobre todas las íes".

La literatura surgida a fines del siglo XIX, no lo olvidemos, tuvo que emprender la hazaña de hacerse o de crearse sus lectores propicios, sacarlos de las nebulosas en que se movian y hacerles ver la pobreza de sus preferencias artísticas, porque en aquellos años ocurria lo que señala Ortega en las Meditaciones del Quijote a propósito de la Restauración española:

31 Obra completa, P. 384.

32 Obra completa, $\$ 402$. En la página siguiente, reitera: "No hablamos de arte nunca". 
"fatalmente lo mediocre y liviano parcció aumentar su densidad. Las motas se hincharon como cerros y Nủñez de Arce pareció un poeta".33

Silva y los modernistas proceden a realizar un drástico juicio final, porque hay que cambiarlo todo: condenan a muerte a la izquierda y ordenan las filas que se salvan a la derecha. En la primera los relamidos lectores de Ohnet; en la segunda, la contrapartida de los mediocres: los selectos, los buenos entendedores los que prolongan la obra en su admiración o en su posibilidad de compartir. En De sobremesa deja Silva testimonio de una apetecida nueva raza de lectores, los que son también, y a su modo, artistas, estetas:

- ¿Por qué no escribes un poema?... - Insistió Sáenz.

-Porque no lo entenderian tal vez, como no entendieron los "Cantos del más allá". . ¿Ya no recuerdan el artículo de Andrés Ramírez, en que me llamó asqueroso pornógrafo y dijo que mis versos eran una mczcla de agua bendita y de cantáridas? Pues esa suerte correría el poema que escribiera. Es que yo no quiero decir sino sugerir, y para que la sugestión se produzca es preciso que el lector sea un artis. ta. En imaginaciones desprovistas de facultades de ese orden, ¿qué efecto produciría la obra de arte? Ninguno. La mitad de ella está en el verso, en la estatua, en el cuadro, la otra en el cerebro del que oye, ve o sueña $\ldots$. $^{34}$

También hay falsos lectores entre los que parecen ejercer la tarea exegética. La burla de Nordau, como ejemplo de esta irreverencia, es frecuente entre los modernistas, que no le perdonaban el haber puesto las manos rudas sobre los escritores que ellos adoraban como verdaderos guías. Silva contrasta Degeneración, tan leido a fines de siglo, con el diario de María Baskirtseff, "la dulcísima rusa muerta en París de genio y de tisis". El "Zoilo de los Homeros que han cantado los dolores y las alegrías de la Psiquis eterna", 35 como llama al alemán, todo lo dañó con sus "rudas manos tudescas", 36 y bien puede aparecer como ídolo de los que se conforman con lo mediocre, sobre los que Silva depone este entusiasmado anatema:

"oh muestras de la calidad corriente de la especie humana, fabrica.

33 Ortega, Meditationes del Quijote. Madrid: Ediciones de la Universidad de Puerto Rico. Revista de Occidente, 1957. p. 87.

34 Obra completa, p. 204.

35 Obra completa, p 211.

36 Idem, ibid. 
das de prisa por el Gran Hacedor, sin hinchazones de músculos y sin afinamientos de nervios, lectores de Ohnet, adoradores de Gaboriau y de Montepin que consideráis como lo supremo del arte los cuadros en que sonríen las venus de pomadas rosadas pintadas por Bouguerau; que os pasmáis oyendo las musiquillas italianas de hace treinta años $\mathrm{y}$ las idiotas pornografías de los café-conciertos y a quienes dejan fríos las dulces ingenuidades de los pintores prerrafaelitas, las sutilezas del arte japonés las grandiosas sinfonías de Wagner, los dolorosos personajes que atraviesan la sombra gris de las novelas de Dostoiewsky, las extraterrestres creaciones de Poe; admiradores de lo mediocre $\mathrm{y}$ de lo fácil a quienes Max Nordau presentaria como prototipos del perfecto equilibrio ..."37

Silva, como muchos de los artistas de Hispanoamérica, se estrelló dramáticamente con la chatura de sus días. El hombre que escribió $D e$ sobremesa no supo a qué lado volver sus pasos, si hasta la crítica de su tiempo iba descaminada y ciega. En una conocida poesia suya, en que Silva se embarca a sí mismo en la burla que traza, el creador, después de lograr unas estrofas de "arte nervioso y nuevo, obra audaz y suprema", las lleva al sumo juez literario:

Complacido en mis versos, con orgullo de artista, les di olor de heliotropos y color de amatista...

Le mostré mi poema a un crítico estupendo...

$\mathrm{Y}$ lo leyó seis veces y me dijo... ¡ No entiendo!

Con su muerte Silva nó hace sino rubricar-más allá de la tinta y de la literatura - su incomodidad de vivir - exacerbada conciencia román. tica- en un mundo que no le comprendía y con el cual no quiso hacerse cómplice ni pactar. El pistoletazo asordinado en esa distante noche bogotana es, por otra parte, el final justo y previsible para el escritor y su prolongación poética en el protagonista de De sobremesa.

The Obio State University

JUAN LOVELUCK

37 Obra completa, p. 260. 